\title{
Article \\ EP4 as a Negative Prognostic Factor in Patients with Vulvar Cancer
}

\author{
Anna Buchholz ${ }^{1}$, Aurelia Vattai ${ }^{1}$, Sophie Fürst ${ }^{1}$, Theresa Vilsmaier ${ }^{1} \mathbb{D}$, Christina Kuhn $^{1,2}$, Elisa Schmoeckel ${ }^{3}$, \\ Doris Mayr ${ }^{3}$, Christian Dannecker ${ }^{1,2}$, Sven Mahner ${ }^{1}$, Udo Jeschke ${ }^{1,2, * \mathbb{C}}$ and Helene H. Heidegger ${ }^{1}$
}

1 Department of Obstetrics and Gynecology, University Hospital, LMU Munich, Marchioninistraße 15, 81377 Munich, Germany; buchholz.anna@web.de (A.B.); aurelia.vattai@med.uni-muenchen.de (A.V.); sophie.fuerst@med.uni-muenchen.de (S.F.); Theresa.Vilsmaier@med.uni-muenchen.de (T.V.); christina.kuhn@uk-augsburg.de (C.K.); christian.dannecker@med.uni-augsburg.de (C.D.); Sven.Mahner@med.uni-muenchen.de (S.M.); Helene.Heidegger@med.uni-muenchen.de (H.H.H.)

2 Department of Obstetrics and Gynecology, University Hospital Augsburg, Stenglinstrasse 2, 86156 Augsburg, Germany

3 Department of Pathology, LMU Munich, Thalkirchner Str. 142, 80337 Munich, Germany; elisa.schmoeckel@med.uni-muenchen.de (E.S.); doris.mayr@med.uni-muenchen.de (D.M.)

* Correspondence: udo.jeschke@med.uni-muenchen.de; Tel.: +49-89-4400-54240

Citation: Buchholz, A.; Vattai, A.; Fürst, S.; Vilsmaier, T.; Kuhn, C.; Schmoeckel, E.; Mayr, D.; Dannecker, C.; Mahner, S.; Jeschke, U.; et al. EP4 as a Negative Prognostic Factor in Patients with Vulvar Cancer. Cancers 2021, 13, 1410. https://doi.org/ $10.3390 /$ cancers13061410

Academic Editor: David Wong

Received: 7 January 2021

Accepted: 17 March 2021

Published: 19 March 2021

Publisher's Note: MDPI stays neutral with regard to jurisdictional claims in published maps and institutional affiliations.

Copyright: (C) 2021 by the authors. Licensee MDPI, Basel, Switzerland. This article is an open access article distributed under the terms and conditions of the Creative Commons Attribution (CC BY) license (https:// creativecommons.org/licenses/by/ $4.0 /)$.
Simple Summary: Within this study we investigated the expression of EP4 in vulvar cancer, its correlation with clinic-pathological parameters, its association with overall survival, and the effect oft EP4 antagonism on vulvar cancer cells, aiming to find a prognostic and potentially targetable marker in vulvar cancer. Cox regression revealed EP4 as an independent negative prognostic factor for overall survival when other factors were taken into account. We could show in vitro that EP4 antagonism attenuates both viability and proliferation of vulvar cancer cells. Further investigation of the EP4 signaling pathway and its role in the micro tumor environment in vulvar cancer could lead to a deeper understanding of the molecular mechanisms of cancer genesis.

Abstract: New prognostic factors and targeted therapies are urgently needed to improve therapeutic outcomes in vulvar cancer patients and to reduce therapy related morbidity. Previous studies demonstrated the important role of prostaglandin receptors in inflammation and carcinogenesis in a variety of tumor entities. In this study, we aimed to investigate the expression of EP4 in vulvar cancer tissue and its association with clinicopathological data and its prognostic relevance on survival. Immunohistochemistry was performed on tumor specimens of 157 patients with vulvar cancer treated in the Department of Obstetrics and Gynecology, Ludwig-Maximilian-University of Munich, Germany, between 1990 and 2008. The expression of EP4 was analyzed using the wellestablished semiquantitative immunoreactivity score (IRS) and EP4 expression levels were correlated with clinicopathological data and patients' survival. To specify the tumor-associated immune cells, immunofluorescence double staining was performed on tissue samples. In vitro experiments including 5-Bromo-2'-Deoxyuridine (BrdU) proliferation assay and 3-(4,5-Dimethylthiazol-2-yl)-2,5diphenyltetrazoliumbromid (MTT) viability assay were conducted in order to examine the effect of EP4 antagonist L-161,982 on vulvar carcinoma cells. EP4 expression was a common finding in in the analyzed vulvar cancer tissue. EP4 expression correlated significantly with tumor size and FIGO classification and differed significantly between keratinizing vulvar carcinoma and nonkeratinizing carcinoma. Survival analysis showed a significant correlation of high EP4 expression with poorer overall survival $(p=0.001)$ and a trending correlation between high EP4 expression and shorter disease-free survival $(p=0.069)$. Cox regression revealed EP4 as an independent prognostic factor for overall survival when other factors were taken into account. We could show in vitro that EP4 antagonism attenuates both viability and proliferation of vulvar cancer cells. In order to evaluate EP4 as a prognostic marker and possible target for endocrinological therapy, more research is needed on the influence of EP4 in the tumor environment and its impact in vulvar carcinoma.

Keywords: EP4; PGE2; COX-2; cancer survival; prognosis; vulvar carcinoma 


\section{Introduction}

Vulva carcinoma is a relatively uncommon tumor, representing about $2-5 \%$ of all gynecological malignancies [1]. It is mainly a disease in postmenopausal women; however, incidence rates have been increasing in recent years, especially in younger women due to the rise in human papilloma virus (HPV) infections [2]. Squamous cell carcinoma is the most common histological subtype, accounting for $80-90 \%$ of all malignancies of the vulva. An estimated $21-43 \%$ of vulva carcinomas worldwide are related to human papilloma virus (HPV) infection [3-5]. The other HPV-independent group, initiated by p53 mutation, is linked to chronic inflammatory skin diseases such as lichen sclerosis [6,7]. Especially in locally advanced tumor and in lymph node positive patient groups, prognosis remains poor. Predominant treatment is radical surgery, often accompanied by adjuvant or neoadjuvant radiotherapy/chemoradiation. However, radical surgery can lead to reduced quality of life and morbidity [8]. Furthermore, treatment options for advanced vulva cancer are limited due to the lack of large prospective randomized clinical trials regarding systemic treatment [9]. In this context, predictive biomarkers and target-based therapies would play an important role in the improvement of clinical outcomes, especially in advanced stages of disease. In recent times, the search for prognostic markers has gained more and more momentum. The role of cyclooxygenase enzyme 2 (COX-2), successional prostaglandin E2 (PGE2) and its receptors have been investigated in many different tumor entities, such as colon cancer, prostate and lung cancers, as well as in breast cancer and gynecological tumors such as ovarian, cervical and endometrial cancers [10-13]. PGE2 is known to play an important role in pain, fever, inflammation, mucosal integrity and vascular homeostasis. Moreover, previous studies demonstrated the pivotal impact of PGE2 in carcinogenesis, tumor growth, metastasis and tumor-associated angiogenesis [14-16]. PGE2 is synthesized from arachidonic acid through NF-kB inducible cyclooxygenase enzyme-2 (COX-2) and mediates its effects through its specific ligands, prostaglandin E2 receptor 1-4 (EP 1-4). Prostaglandin E2 receptors are G-protein coupled receptors activating different signal pathways, including the cAMP/PKA/CREB pathway, the Ras/Raf/MEK/ERK pathway and the GRK/ $\beta$-arrestin/Src/PI3K/GSK3/b-catenin pathway, which subsequently stimulate the transcription of target genes, including cyclin-D1, c-myc and VEGF $[17,18]$. As demonstrated in previous studies, COX-2 inhibitors, such as nonsteroidal anti-inflammatory drugs (NSAIDs) or celecoxib, might be effective in cancer prevention and therapy [19]. However, the possibility of severe cardiovascular side effects limits their application in cancer treatment [20]. Therefore, targeting COX-2 or PGE2 indirectly by their downstream ligands (EP1-4) could be a promising approach.

The objective of this study was to shed light on the role of EP4 receptor expression in vulvar cancer. We investigated the expression of EP4 in vulvar cancer, its correlation with clinicopathological parameters, its association with overall survival, and the effect oft EP4 antagonism on vulvar cancer cells, aiming to find a prognostic and potentially targetable marker in vulvar cancer.

\section{Results}

Of all specimens, we obtained successful EP4 staining from 131 patients. We could find EP4 cytosolic staining (IRS $\geq 1$ ) in $93.9 \%$ (123/131 cases) of cases, with a median IRS of 6 in $9.2 \%$ of cases. High expression (IRS 9-12) was found in $26.7 \%$ of specimens, compared to moderate expression (IRS 6-8) in 26.8\%, weak expression (IRS 3-4) in 26\% and no expression (IRS 0-2) in 20.6\%. In comparison to vulvar cancer specimens, benign tissue of the vulva showed no EP4 expression. Regarding the histological subtype, $91.7 \%$ of the specimens were keratinizing squamous cell carcinomas, $5.1 \%$ were nonkeratinizing squamous cell carcinomas, $1.9 \%$ were verrucous squamous cell carcinomas and $1.3 \%$ were warty squamous cell carcinomas. Clinicopathological characteristics are displayed in Table 1. 
Table 1. Clinicopathological characteristics of the analyzed vulvar carcinoma samples.

\begin{tabular}{|c|c|c|c|}
\hline \multicolumn{2}{|c|}{ Clinicopathologic Parameters } & \multirow[t]{2}{*}{$n$} & \multirow[t]{2}{*}{ Percentage $(\%)$} \\
\hline Histology & & & \\
\hline & Keratinizing & 160 & 90.4 \\
\hline & Warty/basaloid & 17 & 9.6 \\
\hline \multicolumn{4}{|l|}{ Tumor size } \\
\hline & $\mathrm{T} 1$ & 69 & 39 \\
\hline & $\mathrm{T} 2$ & 92 & 52 \\
\hline & $\mathrm{T} 3$ & 9 & 5.1 \\
\hline & missing & 7 & 3.9 \\
\hline \multicolumn{4}{|l|}{ Nodal status } \\
\hline & No & 78 & 44.1 \\
\hline & N1 & 38 & 21.5 \\
\hline & N2 & 12 & 6.8 \\
\hline & missing & 49 & 27.6 \\
\hline \multicolumn{4}{|l|}{ Metastasis } \\
\hline & M0 & 8 & 4.5 \\
\hline & missing & 169 & 95.5 \\
\hline \multicolumn{4}{|l|}{ FIGO } \\
\hline & I & 61 & 34.4 \\
\hline & II & 54 & 30.5 \\
\hline & III & 47 & 26.6 \\
\hline & IV & 9 & 5.1 \\
\hline & missing & 6 & 3.4 \\
\hline \multicolumn{4}{|l|}{ Grading } \\
\hline & G1 & 29 & 16.4 \\
\hline & G2 & 108 & 61 \\
\hline & G3 & 39 & 22 \\
\hline & missing & 1 & 0.6 \\
\hline \multicolumn{4}{|l|}{ P16 status } \\
\hline & Positive & 38 & 21.5 \\
\hline & Negative & 57 & 32.2 \\
\hline & missing & 82 & 46.3 \\
\hline
\end{tabular}

2.1. Correlation between EP4-Positive Staining and Clinicopathological Parameters

We examined the correlation between positive EP4 staining and clinicopathological parameters using Spearmen's test. EP4 did not correlate with p16 status $(p=0.174)$, tumor grading $(p=0.252)$, primary lymph node metastasis $(p=0.357)$, or the number of tumor foci $(p=0.944)$. However, a significant correlation was observed between positive EP4 staining and greater tumor size (pT) $(p<0.001)$ and EP4 and high FIGO classification $(p=0.003)$ (Figure 1). Kruskal-Wallis tests showed significant differences among different FIGO stages $(p=0.014)$ and $\mathrm{pT}(p=0.002)$. In addition, Mann-Whitney $\mathrm{U}$ test revealed that EP4 expression was higher in keratinizing squamous cell carcinoma than nonkeratinizing squamous cell carcinoma $(p=0.024)$. 


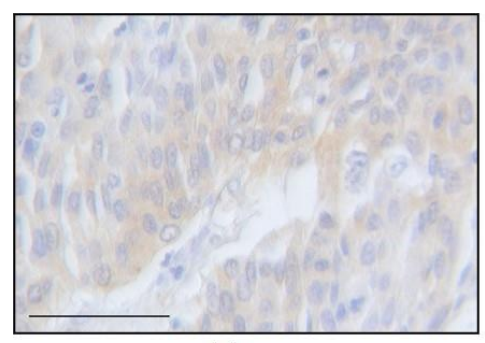

(a)

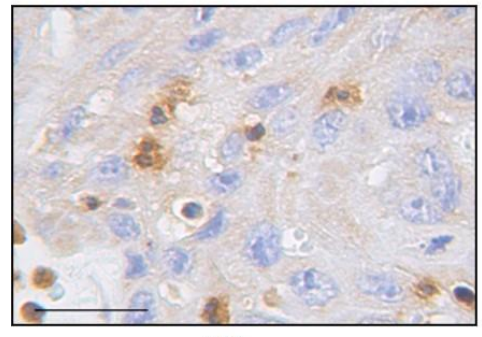

(d)

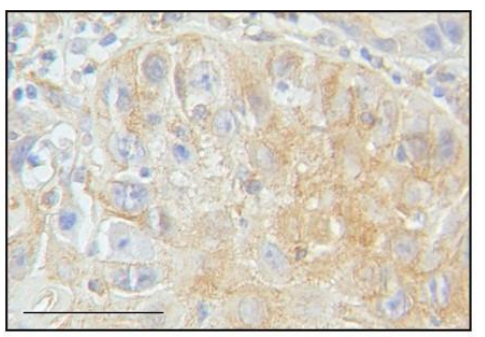

(b)

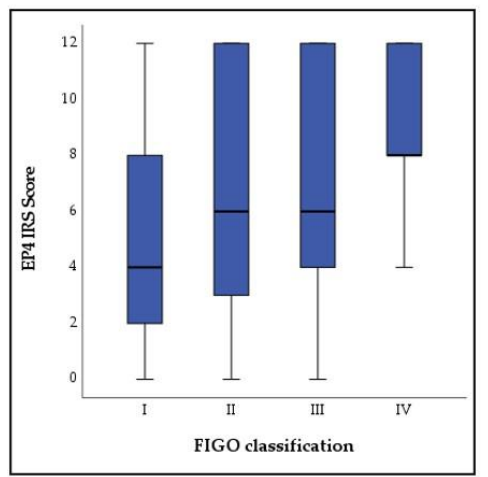

(e)

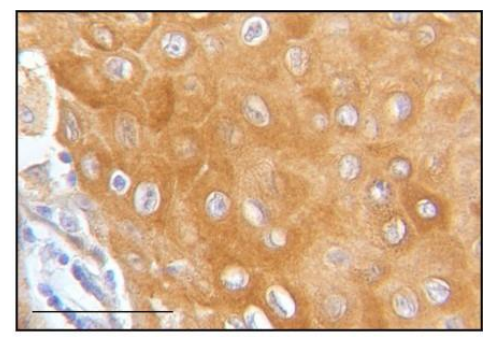

(c)

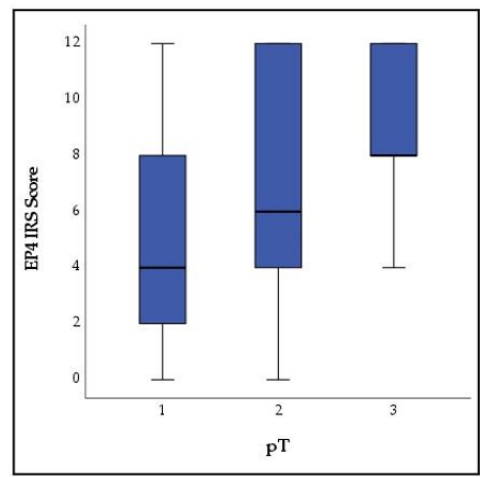

(f)

Figure 1. EP4 expression depending on tumor size and FIGO status. Immunohistochemical staining of EP4 in (a) vulvar cancer with weak expression (immunoreactivity score (IRS) 4), (b) vulvar cancer with moderate expression (IRS 6) and (c) vulvar cancer with strong expression (IRS 12). (d) Vulvar cancer with tumor-associated macrophages. (e,f) EP4 expression correlates with FIGO classification $(p=0.014)$ and tumor size $(p<0.001)$. Magnification and scale bars $(\mathbf{a}-\mathbf{c}) \times 25$ with scale bar representing $100 \mu \mathrm{m}$ and (d) $\times 40$ with scale bar representing $50 \mu \mathrm{m}$.

\subsection{Role of EP4 for Survival}

For three patients no survival follow-up could be obtained. After the observation period, 51 of 157 patients were still alive. In total, 103 of 157 patients died during the observation period; median follow-up time was 4.79 years ( $\mathrm{SD}=6.17$ ).

EP4 positivity was associated with poorer prognosis in overall and disease-free survival. As depicted in the Kaplan-Meier curves, enhanced expression of EP4 (IRS $\geq 3$ ) in vulva cancer patients significantly correlated with shorter overall survival (median estimate 13.7 years vs. 7.2 years; $p=0.001$ ) and showed a trend for a correlation with shorter disease-free survival (median estimate 13.7 years vs. 9.7 years; $p=0.069$ ) time after diagnosis (Figure 2).

\subsection{Cox Regression of EP4 IRS with Clinicopathological Variables}

As described above (methods, statistics), a Cox regression analysis was performed to ascertain the prognostic relevance of EP4 expression when other prognosticators were taken into account. Enhanced EP4 receptor positivity (IRS $\geq 3$ ) was found to be an independent prognostic factor for poorer overall survival $(p=0.016$, hazard ratio $(\mathrm{HR})=2.924,95 \%$ confidence interval (CI)-1.225-6.980) and disease-free survival $(p=0.045$, hazard ratio $(\mathrm{HR})=2.683,95 \%$ confidence interval $(\mathrm{CI})-1.020-7.054)$. Furthermore, age at diagnosis was an independent prognostic factor associated with both, disease-free and overall survival. Moreover, tumor grade and lymph node status at the time of operation were prognostic factors for overall survival. Data of the multivariate analysis is displayed in Table 2. 


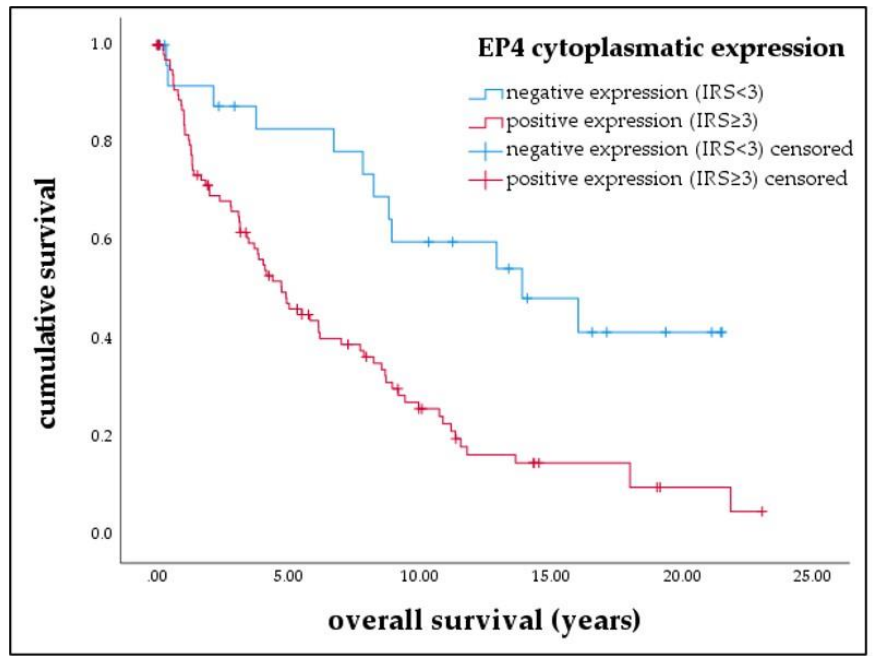

(a)

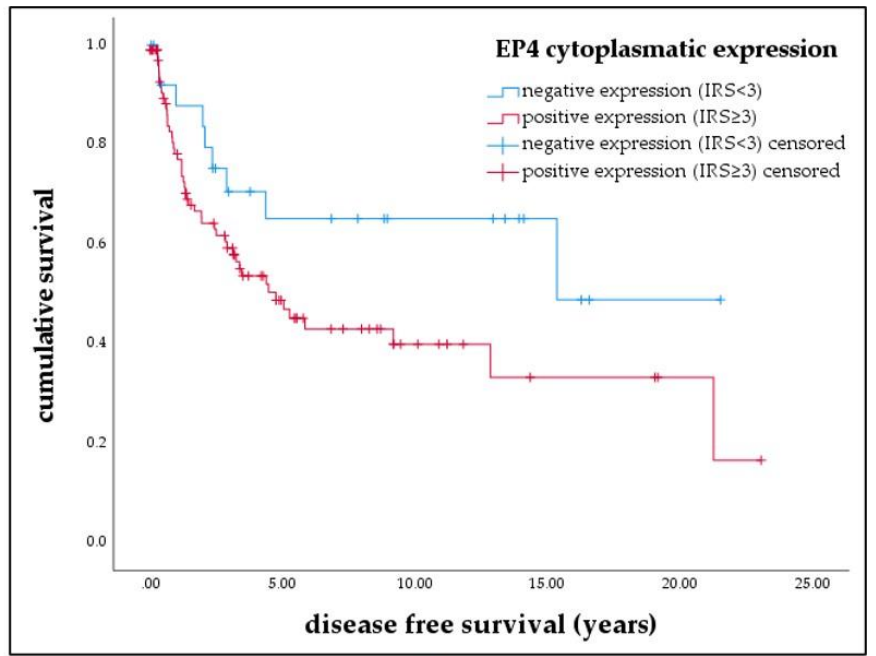

(b)

Figure 2. Kaplan-Meier estimates show that overall survival/disease-free survival is worse in patients with high EP4 expression. (a) Kaplan-Meier survival univariate analysis for the status cytoplasmatic IRS $\geq 3$. Positive expression of EP4 in the cytoplasm significantly reduced overall survival $(p=0.001)(\mathbf{b})$ Kaplan-Meier survival univariate analysis for the status cytoplasmatic IRS $\geq 3$. Positive expression of EP4 lead to decreased disease-free survival ( $p=0.069$ ).

Table 2. Cox regression of clinicopathological variables regarding overall survival.

\begin{tabular}{ccccc}
\hline Co-Variants & Significance & $\begin{array}{c}\text { Hazard Ratio of } \\
\text { Exp (B) }\end{array}$ & $\begin{array}{c}\text { Lower 95\% CI } \\
\text { of Exp (B) }\end{array}$ & $\begin{array}{c}\text { Upper 95\% CI } \\
\text { of Exp (B) }\end{array}$ \\
\hline EP4 IRS $\geq 3$ & $\mathbf{0 . 0 1 6}$ & 2.924 & 1.225 & 6.980 \\
Age & $\mathbf{2 0 . 0 0 1}$ & 1.052 & 1.026 & 1.080 \\
Grading & $\mathbf{0 . 0 0 7}$ & 1.904 & 1.197 & 3.027 \\
pN & $\mathbf{0 . 0 3 3}$ & 1.941 & 1.055 & 3.572 \\
pT & 0.417 & 1.506 & 0.561 & 4.039 \\
FIGO & 0.704 & 0.863 & 0.405 & 1.841 \\
Focalty & 0.688 & 0.843 & 0.366 & 1.940 \\
Histology & 0.877 & 1.092 & 0.360 & 3.307 \\
\hline
\end{tabular}

Bold number characterize $p$-values below 0.05 .

\subsection{EP4 Positive Tumor-Associated Immune Cells}

In total, $36.6 \%$ of the specimens showed EP4 receptor-positive tumor-associated immune cells. These immune cells were identified as macrophages using immunofluorescence double staining with anti-EP4 and anti-CD68 antibodies (Figure 3). EP4 positivity in macrophages did not correlate with clinicopathological parameters. In the subgroup of specimens with EP4-negative macrophages, patients with a tumor IRS $\geq 3$ had a significant worse outcome in terms of disease-free survival (13.2 years vs. 8.3 years; $p=0.29$ ). This effect did not show in the subgroup of specimens with EP4-positive macrophages. EP4 status in macrophages itself had no significant impact on patients' survival.

\subsection{EP4 Antagonist Reduced the Proliferation and Viability of Vulvar Cancer Cells}

EP4 expression was detected in both cell lines. However, EP4 expression was higher in A-431 cells in comparison to SW-954 cells. $\beta$-actin was used as loading control. Benign human epidermal tissue showed insignificant expression of EP4 (Figure S1).

Stimulation of vulvar cancer cells with increasing concentrations of L-161,982 for $72 \mathrm{~h}$ led to decreased viability and proliferation of both A-431 and SW-954 cell lines. A-431 proliferation decreased significantly after stimulation with $10 \mu \mathrm{M}(Z=-3.238 ; p=0.001$; $n=15)$ and $100 \mu \mathrm{M}(Z=-3.408 ; p=0.001 ; n=15)$. SW-954 proliferation also decreased significantly after stimulation with concentrations of $10 \mu \mathrm{M}(Z=-2.472 ; p=0.013 ; n=15)$ 
and $100 \mu \mathrm{M}(\mathrm{Z}=-3.411 ; p=0.001 ; n=15)$ (Figure 4). The effect on proliferation was stronger in SW-954, as its EP4 expression is lower and therefore receptors might be saturated faster with L-161,982. Viability decreased significantly after stimulation with $100 \mu \mathrm{M} \mathrm{L-161,982} \mathrm{in}$ both cell lines $(Z=-3.408 ; p=0.001 ; n=15)$ (Figure 4$)$ and in SW-954 at a concentration of $10 \mu \mathrm{M}(\mathrm{Z}=-2.045, p=0.041 ; n=15)$.
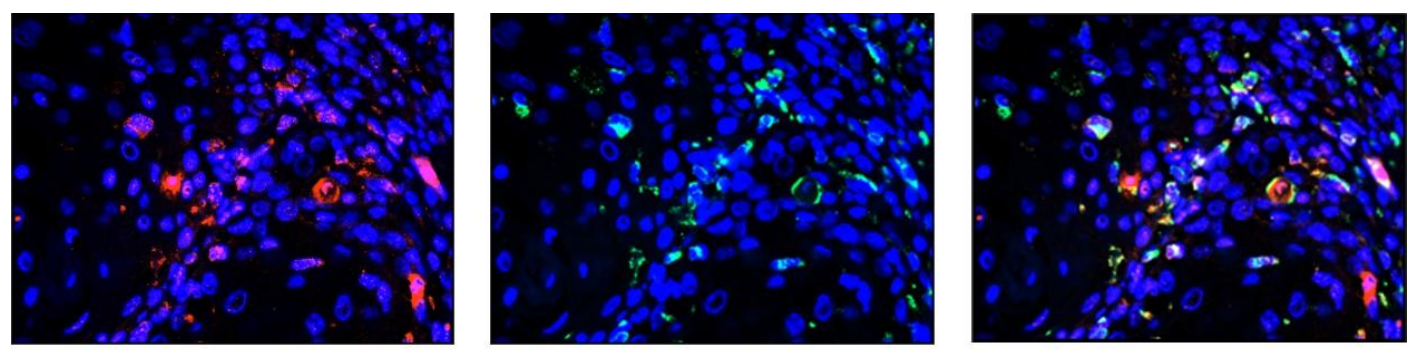

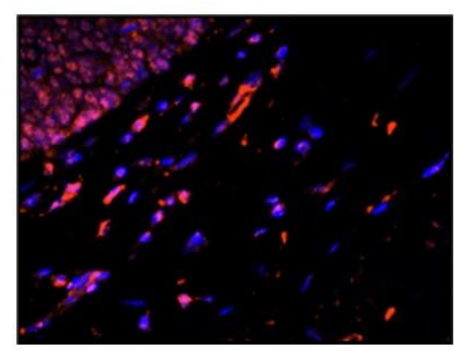

EP4

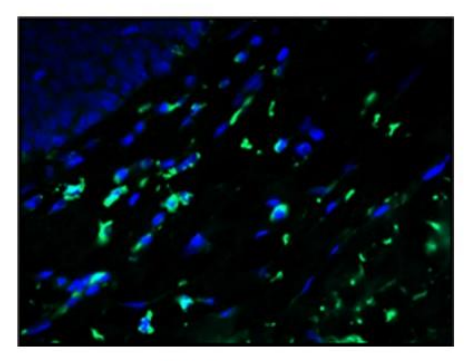

CD68

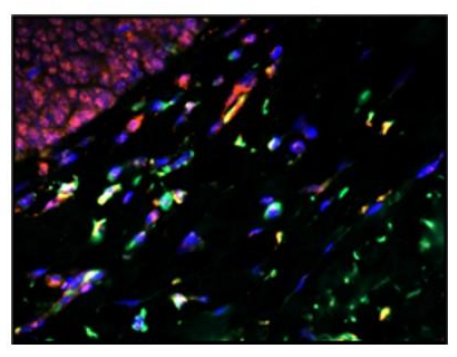

merge

Figure 3. Characterization of immune cells as macrophages using immunofluorescence double staining. Cell nuclei were marked by 4',6-diamidino-2-phenylindole (DAPI) staining (blue): left column shows EP4-positive cells (red), center column shows CD68-positive cells (green) and right column shows the coexpression of both markers CD68 and EP4.

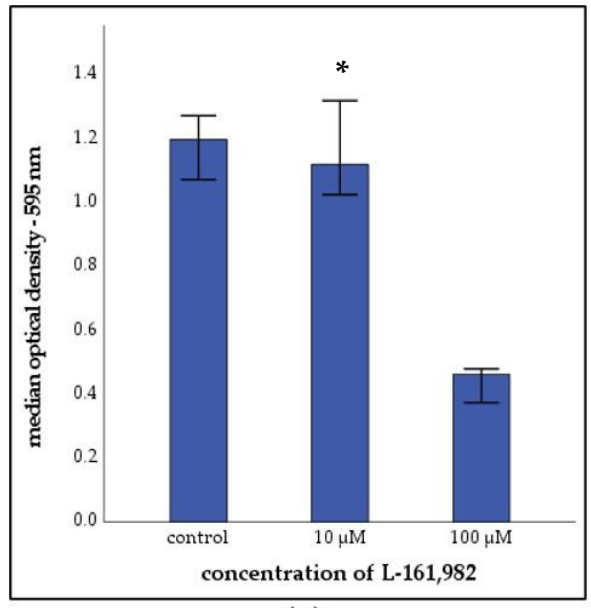

(a)

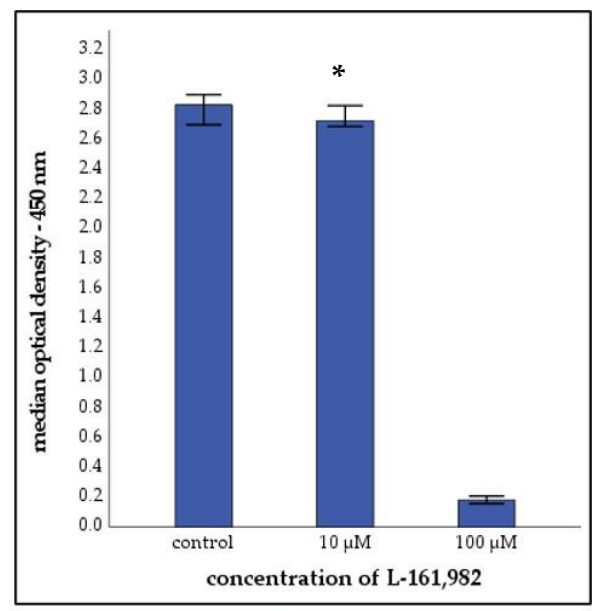

(b)

Figure 4. Cont. 


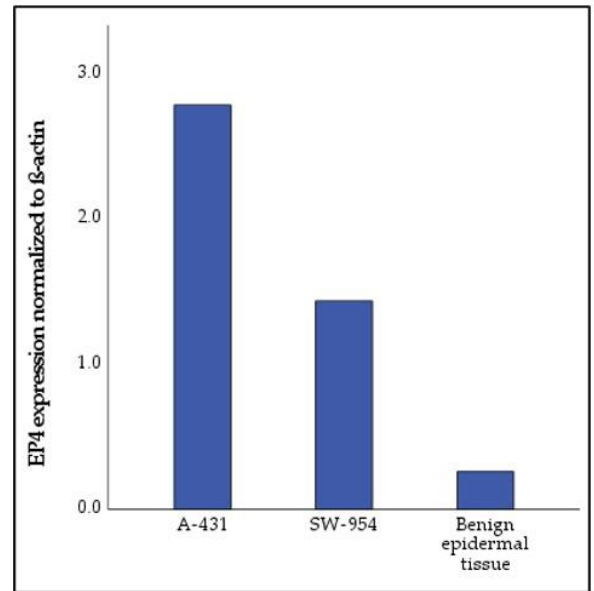

(c)

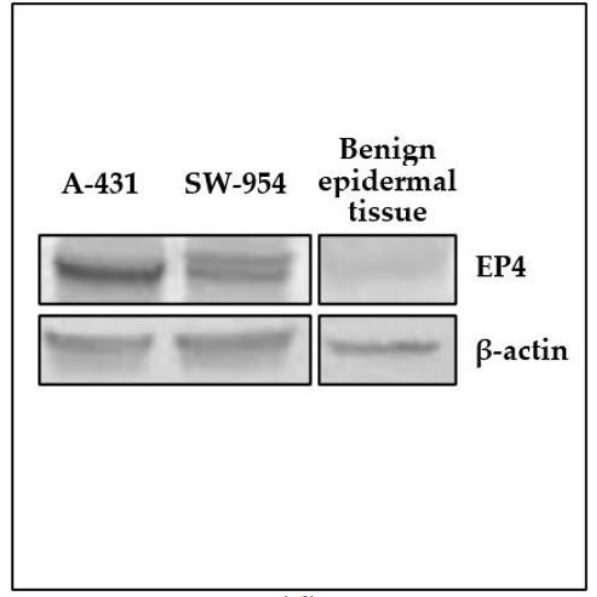

(d)

Figure 4. Incubation of vulvar carcinoma cells with L-161,982. (a) 3-(4,5-Dimethylthiazol-2-yl)2,5-diphenyltetrazoliumbromid (MTT) viability assay of A-431 cells after inhibition with different concentrations of L-161,982 for $72 \mathrm{~h} .{ }^{*} p=0.001$. (b) 5-Bromo-2'-Deoxyuridine (BrdU) proliferation assay of SW-954 calls after inhibition with different concentrations of L-161,982 for $72 \mathrm{~h} .{ }^{*} p=0,001$. (c,d) Western blot analysis of EP4 expression in A-431 and SW-954 cell lines and of benign epidermal tissue. (a,b) Error bars represent 95\% confidence intervals. Wilcoxon test was used for the evaluation of viability/proliferation levels between vehicle and antagonist groups.

\section{Discussion}

Within this study, we observed that EP4 receptor positivity is a frequent finding in vulvar carcinoma, which is the first time EP4 expression and its association with clinicopathological parameters was investigated in vulvar carcinoma. In line with studies showing the impact of COX-2 on carcinogenesis, previous studies also described the effects of EP4 on carcinogenesis in several gynecological cancer models such as breast cancer $[21,22]$, endometrial cancer [23,24], ovarian cancer [25] and cervical cancer [26]. A study by Reader et al. revealed higher expression of EP4 in uterine leiomyosarcoma in comparison to smooth muscle tumors and normal myometrium. It also showed a strongly increased sensitization to docetaxel in sarcoma cells after pretreatment with EP4 antagonist [27]. However, there are only few studies that investigated the role of the COX-2/PGE2/EP receptor axis in vulvar neoplasia. The one study investigating COX-2 expression in vulvar carcinoma reported higher COX-2 expression levels in vulvar neoplasia than in healthy vulvar tissue [28].

In this present study, high EP4 receptor expression correlated with both shorter overall survival and shorter disease-free survival. This is consistent with the study of Fons et al., who reported an association between strong COX-2 expression in vulvar carcinoma and shorter disease-free survival [29]. Moreover, Cox regression analysis revealed EP4 expression, but also age, grading and lymph node metastasis $(\mathrm{pN})$ as independent prognostic factors for overall survival. Our results compare well with findings of previous studies that have proven the importance of lymph node metastasis $(\mathrm{pN})$ and age as prognostic factors in vulvar cancer [30].

Furthermore, we found correlations between higher EP4 expression and FIGO classification, greater tumor size (pT) and the amount of keratin of the tumor. This is in line with an investigation describing significant correlations of higher tumor/stroma COX-2 expression ratio with metastatic lymph node involvement and higher FIGO stage of the tumor [31]. Similar to our results, they detected a trending association between stromal invasion (pT) and COX-2 expression. However, in our analysis EP4 was not associated with lymph node metastasis and grading.

Additionally, we found that EP4 was also detectible in tumor-associated immune cells, which were specified as macrophages by immunofluorescence. Previous inves- 
tigations identified EP4 as the predominant prostaglandin receptor isoform in human macrophages in cell culture and atheroma tissue [32]. Macrophages are known to be very adaptable cells promoting heterogenic effects depending on their changing surrounding microenvironments [33]. They are known to foster tumor progression by different mechanisms including suppression of antitumor immunity and promotion of angiogenesis and cell invasiveness [34]. In addition to its well-known proinflammatory effect, Takayama et al. showed that endogenous $\mathrm{PGE}_{2}$ may act as an anti-inflammatory by suppressing macrophage-derived chemokine production via the EP4 receptor [32]. In our study, the visible trend for a reduction in disease-free survival in the entire patient collective for specimens with tumor EP4 IRS $\geq 3$ was statistically significant in the subgroup of patients with EP4-negative tumor-associated macrophages. Nevertheless, in our study, EP4 positivity in tumor-associated macrophages itself did not correlate with reduced disease-free or overall survival. Moreover, we did not find any correlations with other clinicopathological parameters. Therefore, immunohistochemical analysis in our study provides a preliminary insight into EP4 expression in tumor-associated macrophages and further investigations are needed to understand how EP4 in macrophages modulates cancerogenic mechanisms.

As described earlier, HPV infection plays an important role in carcinogenesis of vulvar carcinoma. HPV encodes for oncogenic proteins such as E7 inactivating tumor suppressor p53, E6 inducing degradation of $\mathrm{pRb}$ and E5, whose oncogenic mechanism has been studied the least. HPV E5 is located in the endoplasmatic reticulum and is described as playing a supporting role for the viral oncoproteins E6 and E7 by trafficking of cytoplasmic membrane proteins, increased epidermal growth factor receptor (EGFR) signaling and activation of the MAPK pathway [35]. Oh et al. studied the effects of HPV E5 protein on PGE2 signaling in cervical cancer cells and described an induction of EP4 by HPV E5 with epidermal growth factor receptor, COX-2, PGE2, EP2 and EP4, protein kinase $\mathrm{A}, \mathrm{CREB}$ and CRE being engaged in this induction [36]. However, in our analysis, we could not find correlations between EP4 expression and p16 status in vulvar carcinoma. Multiple studies could verify p16 as a reliable surrogate for HPV-association in cervical and oropharyngeal tumors [37-40]. However, p16 overexpression was also detected in cases of HPV-independent tumors-this indicates that, in addition to the viral oncogenes E6/7, there must be HPV-independent pathways inducing p16 overexpression [41,42]. Therefore, more studies are needed to examine the accuracy of p16 as a marker for HPV association in vulvar carcinoma and its relationship with the overexpression of EP4. Furthermore, there might be different definitions of p16 positivity in immunohistochemistry [43]. Exclusively strong cytoplasmic and nuclear "block like" staining throughout the whole tumor on slide should be considered as p16-positive [44].

EP4 promotes its tumorigenic effect through several processes in the microtumor environment. Inter alia, previous studies identified PDL-1 expression as being a negative prognosticator in squamous cell carcinoma of the vulva and showed that the number of tumor infiltrating lymphocytes was associated with PD-L1 expression [44]. According to Wang et al., stimulation of PGE2/EP4 signaling pathways resulted in an increased expression of PD-1 in infiltrating CD8+ T-cells in patients with lung cancer [45]. Similar results have been published Miao et. al, who revealed that the combined blockade of $\mathrm{PGE}_{2}$ and PD-1 pathways led to a substantially renovated function of cytotoxic lymphocytes [46]. These results indicate that targeting EP receptors in combination with PD-L1 blockade might be a promising diagnostic or therapeutic option for cancer patients in the future.

We could show in vitro that EP4 antagonism can decrease viability and proliferation in vulvar carcinoma cells, supporting previous studies describing the impact of EP4 in carcinogenesis in other tumor entities [12]. This effect on proliferation was stronger in SW-954, as its EP4 expression is lower and therefore receptors might be saturated faster with L-161,982. Parida et al. showed a diminished tumor viability and proliferation of cervical cancer in vitro as well as in vivo after EP4 antagonism [26]. Additionally, in breast cancer cell lines decreased migration and proliferation was described following a treatment with EP4 antagonists [22]. In a study with colon carcinoma cell lines, L-161,982 
blocked ERK phosphorylation and thereby inhibited proliferation via the Ras-Raf-MEKERK pathway. This effect was the strongest in EP4 regulated pathways compared to the other EP receptors [47].

\section{Materials and Methods}

\subsection{Patients}

The analyzed study group consisted of 177 patients who underwent surgery at the Department of Gynecology and Obstetrics in Munich between 1990 and 2008. Of these 177 samples, 157 were available for immunohistochemical staining. As negative and positive controls for immunohistochemical staining protocols, we used placenta tissue, also obtained from the Department of Gynecology and Obstetrics in Munich. Patients' median age was 69.5 years (range 20-96 years) and overall median survival was 7.03 years. Immediately after resection, the vulva cancer tissue was fixated in formalin solution and embedded in paraffin.

\subsection{Immunohistochemistry}

The paraffin embedded slides were stained immunohistochemically, as previously described in [48].

First, the slides were dewaxed with xylol for $20 \mathrm{~min}$, washed in alcohol, then incubated in methanol with $3 \% \mathrm{H}_{2} \mathrm{O}_{2}$ for $20 \mathrm{~min}$ in order to inhibit the endogen peroxidases and were finally rehydrated in descending alcohol. In order to unmask the antigen after formalin-fixation-associated protein-agglomeration, the slides were heated in sodium citrate buffer $(\mathrm{pH}=6.0)(0.1 \mathrm{M}$ citric acid and $0.1 \mathrm{M}$ sodium citrate in distilled water $)$ using a pressure cooker. After cooling and washing in PBS, we used blocking solution (Reagent 1, Zytochem-Plus HRP Polymer-Kit (mouse/rabbit) Zytomed Systems Berlin, Germany) for $20 \mathrm{~min}$ to avoid nonspecific binding of the primary antibodies. We incubated the slides with the primary anti-EP4 antibody (polyclonal rabbit IgG, HPA012756, Sigma Aldrich, St.Louis, MO, USA) for $16 \mathrm{~h}$, before detecting it with the polymer method via secondary complex (ZytoChem Plus HRP Polymer System mouse/rabbit,) and the chromogen diaminobenzidine (Dako, Hamburg, Germany).

The expression of EP4 in the specimens was analyzed with a Leitz (Wetzlar, Germany) microscope using the well-established semiquantitative immunoreactivity score (IRS). The IRS was derived by multiplying the intensity of the staining $(0=$ no, $1=$ weak, $2=$ moderate, $3=$ strong staining) with the percentage of stained cells $(0=$ no staining, $1 \leq 10 \%$ positive cells, $2=11-50 \%$ positive cells, $3 \geq 50 \%$ positive cells) [49]. Samples with an IRS of 0,1 or 2 were classified as EP4-negative, and samples with an IRS of 3 or higher were counted as EP4-positive. Eventually, both groups were compared for clinicopathological parameters, progression-free and overall survival. Tumor-associated immune cells were counted per field of view $(25 \times$ lens) and dichotomized in positive ( $>4$ per field of view) and negative $(\leq 4$ per field of view) immune cell staining. Mean values of infiltrating immune cells detected in three different spots of the same individual were calculated [50]. As negative and positive controls, we used placenta tissue, also obtained from the Department of Gynecology and Obstetrics in Munich.

P16 staining was performed on a Ventana Benchmark XT autostainer (Ventana Medical Systems, Oro Valley, AZ, USA) using the p16-primary antibody (clone E6H4E6H4/p16 ${ }^{\text {Ink4a }}$, Ventana, ready-to-use) and the XT UltraView diaminobenzidine kit (Vector Laboratories, Burlingame, CA, USA) followed by hematoxylin counterstaining (Vector Laboratories). Samples were classified as p16-positive when strong cytoplasmic and nuclear staining was observed throughout the whole tumor on slide ("block" staining). Cases showing a weak or patchy staining were classified p16-negative.

\subsection{Immunofluorescence}

To clearly identify the tumor-associated immune cells, immunofluorescence double staining for EP4 and the macrophage marker CD68 was performed. The tissue slides were 
preprocessed as they were for immunohistochemistry, as described above. The next steps included the application of blocking solution (UltraVision Protein Block; Thermo Fisher Scientific, Waltham, MA, USA)

The slides were pretreated as they were for immunohistochemistry. To prevent unspecific binding of the primary antibody, a blocking solution (UltraVision Protein Block; Thermo Fisher Scientific) was applied to the slides for $15 \mathrm{~min}$. The slides were incubated for $16 \mathrm{~h}$ with a mixed solution of the primary antibodies. After washing the slides thoroughly with PBS, fluorophore-labeled secondary antibodies were applied for $30 \mathrm{~min}$ in the dark at room temperature. Finally, the slides were covered with mounting medium (Vectashield H-1200; Vector Laboratories) containing 4',6-diamidino-2-phenylindole (DAPI) for nuclear counterstaining. All double stainings were observed at $20 \times, 40 \times$ and $63 \times$ magnifications using a confocal laser microscope (Axiophot fluorescent microscope; Zeiss, Oberkochen, Germany) and analyzed with the corresponding software AxioVision.

\subsection{Cell Culture}

The human carcinoma cell lines A-431 and SW-954 used in our study as vulva carcinoma models were purchased from the American Type Culture Collection (Manassas, VA, USA). The cells were cultured in Dulbecco's Modified Eagle's Medium (DMEM) (Biochrom, Berlin, Germany) containing 10\% fetal bovine serum (FCS, Thermo Fisher Scientific) without antibiotic in a humidified incubator at $37^{\circ} \mathrm{C}$ with $5 \% \mathrm{CO}_{2}$ saturation. In preparation for each experiment, cells were counted using a Neubauer cell chamber.

\subsection{Inhibition with EP4 Antagonist L-161,982}

A-431 and SW-954 cells were seeded into 96-well plates at a density of $1 \times 10^{4}$ cells $/ 100 \mu \mathrm{L} /$ well in quintuplicates and incubated over night for $24 \mathrm{~h}$. The next day, $100 \mu \mathrm{L}$ of fresh medium containing different concentrations $(2,20$ or $200 \mu \mathrm{M})$ of EP4 antagonist L-161,982 (Tocris Bioscience, Bristol, UK) or the vehicle DMSO as a control were added to each well, resulting in a final concentration of 1,10 or $100 \mu \mathrm{M}$. Afterwards, cells were incubated for $72 \mathrm{~h}$.

\subsection{Viability Assay}

After stimulation with the EP4 antagonist L-161,982 for $72 \mathrm{~h}$, MTT assay was used to examine its effects on the viability of the cells. To each well, $20 \mu \mathrm{g}$ 3-(4,5-dimethylthiazol-2-yl)2,5-diphenyltetrazoliumbromid (MTT) (Sigma-Aldrich) solution $(5 \mathrm{mg} / \mathrm{mL}$ in phosphatebuffered saline PBS) was then added and incubated for $1.5 \mathrm{~h}$ at $37^{\circ} \mathrm{C}$. The culture medium along with MTT was then removed. A total of $200 \mu \mathrm{L} \mathrm{DMSO/well} \mathrm{was} \mathrm{added} \mathrm{and} \mathrm{mixed}$ thoroughly on the shaker for $5 \mathrm{~min}$ at room temperature to dissolve the formazan crystals. Finally, optical density was quantified at $595 \mathrm{~nm}$ using an Elx800 universal Microplate Reader. The experiment was repeated three times in order to ensure reliability.

\subsection{Proliferation Assay}

After stimulation with the EP4 antagonist L-161,982 for 72 h, 5-bromo-2'-deoxyuridine (BrdU) incorporation assay (Roche, Basel, Swizzerland) was used to determine the cell proliferation according to the manufacturer's protocols. For this purpose, BrdU was added in a concentration of $10 \mu \mathrm{M} /$ well, and the cells were reincubated for $24 \mathrm{~h}$. The medium was removed from the cells, and $200 \mu \mathrm{L}$ of Fix-Denat was added to each well and incubated for $30 \mathrm{~min}$ at room temperature. The supernatant was removed and $100 \mu \mathrm{L}$ of Anti-BrdU-POD solution was added to the cells for $90 \mathrm{~min}$, binding the BrdU, which was incorporated before in the newly synthesized DNA. In the next step, the wells were carefully washed three times with PBS and subsequently the cells were incubated with a substrate solution (tetramethyl-benzidine) in the dark at room temperature for about 20 min until an increasing blue color became visible. The reaction was stopped by adding $25 \mu \mathrm{L}$ of $1 \mathrm{M}$ sulfuric acid. Finally, optical density was quantified at $450 \mathrm{~nm}$ using an Elx800 
universal Microplate Reader. The experiment was repeated three times in order to ensure reliability.

\subsection{Western Blot}

First, cell lysates of $5 \times 10^{6}$ cells per cell line (SW-954 and A-431) were produced using a buffer containing $1 \mathrm{~mL}$ of RIPA buffer (Sigma Aldrich, R0278-50ML), $2 \mu \mathrm{L}$ protease Inhibitor cocktail (Sigma Aldrich, P8340) and $10 \mu \mathrm{L}$ Natrium-Vanadate. Human keratinozytes were obtained from the Department of Dermatology, University Hospital Augsburg (gift of Prof. Dr. J. Welzel). Lysates of benign human epidermal tissue in liquid nitrogen were produced by additionally using an ultrasonic sonifier cell disruptor B15 (Branson, Brookfield, CT, USA). Proteins were separated by SDS-PAGE electrophoresis and transferred to PVDF membranes. After $2 \mathrm{~h}$ incubation in a blocking solution containing TBS/Tween/milk powder, the membranes were incubated at room temperature for $16 \mathrm{~h}$ overnight with the primary antibody dilutions polyclonal rabbit anti-EP4 (1:300; ab217966, Abcam, Cambridge, US) and monoclonal mouse anti- $\beta$-actin (1:1000, Sigma Aldrich). The next day, the membranes were washed and incubated for $1 \mathrm{~h}$ at room temperature with the corresponding 1:1000 dilution of alkaline phosphatase-conjugated secondary antibodies. Staining was carried out using 5-bromo-4-chloro-3-indolyle phosphate/nitroblue-tetrazolium chloride (Promega, Madison, WI, USA) in 0.1-M Tris-HCl, $0.15 \mathrm{M} \mathrm{NaCl}, \mathrm{pH}$ 9.5. Western blot images were scanned and quantified with Quantity One 4.6.7 (Bio-Rad, Hercules, USA) (Figure S1). Staining intensity of the Western blots was normalized to $\beta$-actin staining and is presented in absolute number of densitometry analysis.

\subsection{Statistics}

Data analysis was performed with the Statistical Product and Service Solutions 25 (PASW Statistic, SPSS Inc., IBM, Chicago, IL, USA). Spearmen's test was used to test for correlations between immunohistochemically staining and clinicopathological parameters. Nonparametric tests (Mann-Whitney U and Kruskal-Wallis tests) were used for group comparisons regarding the IRS of the prostaglandin receptors between independent clinical and pathological subgroups and are displayed as boxplot graphs. A Wilcoxon test was used for the evaluation of viability/proliferation levels between vehicle and antagonist groups. Survival times were analyzed by Kaplan-Meier curves and log-rank testing (Mantel Cox). Cut-off points were acquired by the receiver operator curve (ROC). We considered $p$ values $\leq 0.05$ as statistically significant.

\section{Conclusions}

In conclusion, we observed that EP4 is an independent prognostic factor for the overall survival in vulvar carcinoma. In addition, the immunohistochemical staining of EP4 is correlated to FIGO classification and tumor size pT, whereas EP4 positivity seems to be independent from p16 status. We could show in vitro that EP4 antagonism attenuates viability and proliferation of vulvar cancer cells. Further investigation of the EP4 signaling pathway and its role in the micro tumor environment in vulvar cancer could lead to a deeper understanding of the molecular mechanisms of cancer genesis.

Supplementary Materials: The following are available online at https:/ / www.mdpi.com/2072-669 4/13/6/1410/s1, Figure S1: uncropped western blots with molecular weight markers.

Author Contributions: A.B. participated in design and coordination of the study, performed immunohistochemistry assays and analysis, conducted the cell culture experiments and performed the statistical analysis. C.K. performed technical assistance in immunohistochemistry assays and analysis. A.B. and H.H.H. wrote the manuscript. A.V., S.F. T.V. and C.D. participated in the design of the study and carefully read the manuscript for important intellectual content. E.S. and D.M. supervised immunohistochemistry as a gynecologic pathologist and participated in immunohistochemistry analysis as well as in the design and coordination of the study. S.M. revised the manuscript for important intellectual content. U.J. and H.H.H. conceived the study and participated in its design and 
coordination and approved the final version of the manuscript. All authors analyzed and interpreted the data and read and approved the final manuscript.

Funding: The authors acknowledge financial support by the Friedrich-Baur-Stiftung (registration number 33/19) for Helene H. Heidegger 36/18.

Institutional Review Board Statement: This study is in accordance with the ethical standards of the institutional research committee and with the 1964 Helsinki Declaration and its later amendments or comparable ethical standards. Patient data were anonymized. The study was approved by the ethics committee of the Ludwig-Maximilian-University Munich (reference number 19-261). During experimental and statistical analyses, the authors were blinded for clinicopathological parameters and survival data. The cancer tissue was no longer needed for clinical tests as histopathological diagnostics after surgery had been completed prior to this study.

Informed Consent Statement: When the current study was performed, all diagnostic procedures were completed, and the patients' data were anonymized. The ethical principles adopted in the Declaration of Helsinki 1975 have been respected. As per the declaration of our ethics committee, no written informed consent of the participants or permission to publish is needed given the circumstances described above. Researchers were blinded from patient data during experimental and statistical analysis.

Data Availability Statement: The data presented in this study are available on request from the corresponding author. The data are not publicly available due to ethical issues.

Acknowledgments: The authors thank Martina Rahmeh for their excellent technical assistance. In addition, we thank Julia Welzel (Head of the Department of Dermatology, University Hospital Augsburg) for the gift of human keratinozytes.

Conflicts of Interest: S.M. reports grants and personal fees from AstraZeneca, personal fees from Clovis, grants and personal fees from Medac, and grants and personal fees from MSD. He also reports personal fees from Novartis, grants and personal fees from PharmaMar, grants and personal fees from Roche, personal fees from Sensor Kinesis, grants and personal fees from Tesaro, and grants and personal fees from Teva, outside the submitted study. C.D. reports personal fees from MSD, Roche, Sanofi and Tesaro outside the submitted study. All other authors declare no conflict of interest.

\author{
Abbreviations \\ BrdU bromodeoxyuridine \\ cAMP cyclic adenosine monophosphate \\ CI confidence interval \\ COX-2 cyclooxygenase-2 \\ CREB CAMP response element-binding protein \\ DAPI 4',6-diamidino-2-phenylindole \\ DMEM Dulbecco's modified Eagle's medium \\ DMSO dimethyl sulfoxid \\ EP4 prostaglandin E2 receptor 4 \\ FIGO Fédération Internationale de Gynécologie et d'Obstétrique \\ HPV Human papillomavirus \\ HR hazard ratio \\ IRS immunoreactive score \\ MTT 3-(4,5-dimethylthiazol-2-yl)-2,5-diphenyltetrazoliumbromid \\ PBS phosphate buffered saline \\ PD-L1 programmed death-ligand 1 \\ PGE2 prostaglandin E2 \\ PKA protein kinase A \\ ROC receiver operating characteristic \\ VEGF vascular endothelial growth factor
}




\section{References}

1. Rogers, L.J.; Cuello, M.A. Cancer of the vulva. Int. J. Gynaecol. Obstet. 2018, 143, 4-13. [CrossRef] [PubMed]

2. Kang, Y.J.; Smith, M.; Barlow, E.; Coffey, K.; Hacker, N.; Canfell, K. Vulvar cancer in high-income countries: Increasing burden of disease. Int. J. Cancer 2017, 141, 2174-2186. [CrossRef]

3. de Sanjose, S.; Alemany, L.; Ordi, J.; Tous, S.; Alejo, M.; Bigby, S.M. Worldwide human papillomavirus genotype attribution in over 2000 cases of intraepithelial and invasive lesions of the vulva. Eur. J. Cancer 2013, 49, 3450-3461. [CrossRef]

4. Halec, G.; Alemany, L.; Quiros, B.; Clavero, O.; Höfler, D.; Alejo, M.; Quint, W.; Pawlita, M.; Bosch, F.X.; on behalf of the HPV VVAP Study Group; et al. Biological relevance of human papillomaviruses in vulvar cancer. Mod. Pathol. 2017, 30, 549-562. [CrossRef] [PubMed]

5. de Martel, C.; Ferlay, J.; Franceschi, S.; Vignat, J.; Bray, F.; Forman, D.; Plummer, M. Global burden of cancers attributable to infections in 2008: A review and synthetic analysis. Lancet Oncol. 2012, 13, 607-615. [CrossRef]

6. Carlson, J.A.; Ambros, R.; Malfetano, J.; Ross, J.; Grabowski, R.; Lamb, P.; Figge, H.; Mihm, M.C. Vulvar lichen sclerosus and squamous cell carcinoma: A cohort, case control, and investigational study with historical perspective; implications for chronic inflammation and sclerosis in the development of neoplasia. Hum. Pathol. 1998, 29, 932-948. [CrossRef]

7. Vanin, K.; Scurry, J.; Thorne, H.; Yuen, K.; Ramsay, R.G. Overexpression of wild-type p53 in lichen sclerosus adjacent to human papillomavirus-negative vulvar cancer. J. Investig. Dermatol 2002, 119, 1027-1033. [CrossRef]

8. Mert, I.; Cliby, W.; Bews, K.; Habermann, E.; Dowdy, S. Evidence-based wound classification for vulvar surgery: Implications for risk adjustment. Gynecol. Oncol. 2019, 154, 280-282. [CrossRef]

9. Mahner, S.; Prieske, K.; Grimm, D.; Trillsch, F.; Prieske, S.; Von Amsberg, G.; Petersen, C.; Mueller, V.; Jaenicke, F.; Woelber, L. Systemic treatment of vulvar cancer. Expert Rev. Anticancer Ther. 2015, 15, 629-637. [CrossRef]

10. Wang, D.; DuBois, R.N. The role of COX-2 in intestinal inflammation and colorectal cancer. Oncogene 2010, 29, 781-788. [CrossRef]

11. Howe, L.R. Inflammation and breast cancer. Cyclooxygenase/prostaglandin signaling and breast cancer. Breast Cancer Res. 2007, 9, 210. [CrossRef]

12. Ye, Y.; Wang, X.; Jeschke, U.; Von Schönfeldt, V. COX-2-PGE2-EPs in gynecological cancers. Arch. Gynecol Obstet. 2020, 301, 1365-1375. [CrossRef] [PubMed]

13. Wang, D.; Dubois, R.N. Eicosanoids and cancer. Nat. Rev. Cancer 2010, 10, 181-193. [CrossRef]

14. Narumiya, S.; Sugimoto, Y.; Ushikubi, F. Prostanoid Receptors: Structures, Properties and Functions. Physiol. Rev. 1999, 79, 1193-1226. [CrossRef] [PubMed]

15. Konya, V.; Marsche, G.; Schuligoi, R.; Heinemann, A. E-type prostanoid receptor 4 (EP4) in disease and therapy. Pharmacol. Ther. 2013, 138, 485-502. [CrossRef] [PubMed]

16. Williams, C.S.; Mann, M.; DuBois, R.N. The role of cyclooxygenases in inflammation, cancer, and development. Oncogene 1999, 18, 7908-7916. [CrossRef]

17. Yokoyama, U.; Iwatsubo, K.; Umemura, M.; Fujita, T.; Ishikawa, Y. The Prostanoid EP4 Receptor and Its Signaling Pathway. Pharmacol. Rev. 2013, 65, 1010-1052. [CrossRef]

18. O'Callaghan, G.; Houston, A. Prostaglandin E2 and the EP receptors in malignancy: Possible therapeutic targets? Br. J. Pharmacol. 2015, 172, 5239-5250. [CrossRef]

19. Gupta, R.A.; DuBois, R.N. Colorectal cancer prevention and treatment by inhibition of cyclooxygenase-2. Nat. Rev. Cancer 2001, 1, 11-21. [CrossRef]

20. Mukherjee, D.; Nissen, S.E.; Topol, E.J. Risk of Cardiovascular Events Associated With Selective COX-2 Inhibitors. JAMA 2001, 286, 954-959. [CrossRef]

21. Majumder, M.; Nandi, P.; Omar, A.; Ugwuagbo, K.C.; Lala, P.K. EP4 as a Therapeutic Target for Aggressive Human Breast Cancer. Int. J. Mol. Sci. 2018, 19, 1019. [CrossRef]

22. Ma, X.; Kundu, N.; Rifat, S.; Walser, T.; Fulton, A.M. Prostaglandin E Receptor EP4 Antagonism Inhibits Breast Cancer Metastasis. Cancer Res. 2006, 66, 2923-2927. [CrossRef] [PubMed]

23. Ke, J.; Yang, Y.; Che, Q.; Jiang, F.; Wang, H.; Chen, Z.; Zhu, M.; Tong, H.; Zhang, H.; Yan, X.; et al. Prostaglandin E2 (PGE2) promotes proliferation and invasion by enhancing SUMO-1 activity via EP4 receptor in endometrial cancer. Tumour Biol. 2016, 37, 12203-12211. [CrossRef] [PubMed]

24. Jabbour, H.N.; Milne, S.A.; Williams, A.R.W.; Anderson, R.A.; Boddy, S.C. Expression of COX-2 and PGE synthase and synthesis of PGE(2)in endometrial adenocarcinoma: A possible autocrine/paracrine regulation of neoplastic cell function via EP2/EP4 receptors. Br. J. Cancer 2001, 85, 1023-1031. [CrossRef] [PubMed]

25. Spinella, F.; Rosanò, L.; Di Castro, V.; Natali, P.G.; Bagnato, A. Endothelin-1-induced prostaglandin E2-EP2, EP4 signaling regulates vascular endothelial growth factor production and ovarian carcinoma cell invasion. J. Biol. Chem. 2004, 279, 46700-46705. [CrossRef]

26. Parida, S.; Pal, I.; Parekh, A.; Thakur, B.; Bharti, R.; Das, S.; Mandal, M. GW627368X inhibits proliferation and induces apoptosis in cervical cancer by interfering with EP4/EGFR interactive signaling. Cell Death Dis. 2016, 7, e2154. [CrossRef] [PubMed]

27. Reader, J.; Harper, A.K.; Legesse, T.; Staats, P.N.; Goloubeva, O.; Rao, G.G.; Fulton, A.; Roque, D.M. EP4 and Class III $\beta$-Tubulin Expression in Uterine Smooth Muscle Tumors: Implications for Prognosis and Treatment. Cancers 2019, 11, 1509. [CrossRef] [PubMed] 
28. Mitchell, A.; Newton, J.M.; Brite, K.; Einspahr, J.; Ellis, M.; Davis, J.; Nuno, T.; Alberts, D.S.; Garcia, F. Cyclooxygenase 2 expression in cervical intraepithelial neoplasia and vulvar cancer. J. Low Genit. Tract. Dis. 2007, 11, 80-85. [CrossRef]

29. Fons, G.; Burger, M.P.M.; Kate, F.J.W.T.; Van Der Velden, J. Assessment of promising protein markers for vulva cancer. Int. J. Gynecol. Cancer 2009, 19, 756-760. [CrossRef]

30. Woelber, L.; Mahner, S.; Voelker, K.; Zu Eulenburg, C.; Gieseking, F.; Choschzick, M.; Jaenicke, F.; Schwarz, J. Clinicopathological prognostic factors and patterns of recurrence in vulvar cancer. Anticancer Res. 2009, 29, 545-552.

31. Ferrandina, G.; Ranelletti, F.O.; Salutari, V.; Gessi, M.; Legge, F.; Zannoni, G.F.; Scambia, G.; Lauriola, L. Expression of cyclooxygenase-2 (COX-2) in non-neoplastic and neoplastic vulvar epithelial lesions. Gynecol. Oncol. 2004, 92, 537-544. [CrossRef] [PubMed]

32. Takayama, K.; García-Cardeña, G.; Sukhova, G.K.; Comander, J.; Gimbrone, M.A., Jr.; Libby, P. Prostaglandin E2 suppresses chemokine production in human macrophages through the EP4 receptor. J. Biol. Chem. 2002, 277, 44147-44154. [CrossRef] [PubMed]

33. Van Overmeire, E.; Laoui, D.; Keirsse, J.; Van Ginderachter, J.A.; Sarukhan, A. Mechanisms driving macrophage diversity and specialization in distinct tumor microenvironments and parallelisms with other tissues. Front. Immunol. 2014, 5, 127. [CrossRef] [PubMed]

34. Ruffell, B.; Affara, N.I.; Coussens, L.M. Differential macrophage programming in the tumor microenvironment. Trends Immunol. 2012, 33, 119-126. [CrossRef]

35. Moody, C.A.; Laimins, L.A. Human papillomavirus oncoproteins: Pathways to transformation. Nat. Rev. Cancer 2010, 10, 550-560. [CrossRef] [PubMed]

36. Oh, J.-M.; Kim, S.-H.; Lee, Y.-I.; Seo, M.; Kim, S.-Y.; Song, Y.-S.; Kim, W.-H.; Juhnn, Y.-S. Human papillomavirus E5 protein induces expression of the EP4 subtype of prostaglandin E2 receptor in cyclic AMP response element-dependent pathways in cervical cancer cells. Carcinogenesis 2009, 30, 141-149. [CrossRef]

37. Prigge, E.S.; Arbyn, M.; von Knebel Doeberitz, M.; Reuschenbach, M. Diagnostic accuracy of p16(INK4a) immunohistochemistry in oropharyngeal squamous cell carcinomas: A systematic review and meta-analysis. Int. J. Cancer 2017, 140, 1186-1198. [CrossRef]

38. Tan, L.S.Y.; Fredrik, P.; Ker, L.; Yu, F.G.; Wang, D.Y.; Goh, B.C.; Loh, K.S.; Lim, C.M. High-risk HPV genotypes and P16INK4a expression in a cohort of head and neck squamous cell carcinoma patients in Singapore. Oncotarget 2016, 7, 86730-86739. [CrossRef]

39. Sano, T.; Oyama, T.; Kashiwabara, K.; Fukuda, T.; Nakajima, T. Expression status of p16 protein is associated with human papillomavirus oncogenic potential in cervical and genital lesions. Am. J. Pathol. 1998, 153, 1741-1748. [CrossRef]

40. Keating, J.T.; Cviko, A.; Riethdorf, S.; Riethdorf, L.; Quade, B.J.; Sun, D.; Duensing, S.; Sheets, E.; Munger, K.; Crum, C. Ki-67, cyclin E, and p16INK4 are complimentary surrogate biomarkers for human papilloma virus-related cervical neoplasia. Am. $J$. Surg. Pathol. 2001, 25, 884-891. [CrossRef]

41. Sznurkowski, J.J.; Żawrocki, A.; Biernat, W. The overexpression of p16 is not a surrogate marker for high-risk human papilloma virus genotypes and predicts clinical outcomes for vulvar cancer. BMC Cancer 2016, 16, 465. [CrossRef] [PubMed]

42. Riethdorf, S.; Neffen, E.F.; Cviko, A.; Löning, T.; Crum, C.P.; Riethdorf, L. p16INK4A expression as biomarker for HPV 16-related vulvar neoplasias. Hum. Pathol. 2004, 35, 1477-1483. [CrossRef] [PubMed]

43. Liu, Y.; Alqatari, M.; Sultan, K.; Ye, F.; Gao, D.; Sigel, K.; Zhang, D.; Kalir, T. Using p16 immunohistochemistry to classify morphologic cervical intraepithelial neoplasia 2: Correlation of ambiguous staining patterns with HPV subtypes and clinical outcome. Hum. Pathol. 2017, 66, 144-151. [CrossRef] [PubMed]

44. Czogalla, B.; Pham, D.; Trillsch, F.; Rottmann, M.; Gallwas, J.; Burges, A.; Mahner, S.; Kirchner, T.; Jeschke, U.; Mayr, D.; et al PD-L1 expression and survival in p16-negative and -positive squamous cell carcinomas of the vulva. J. Cancer Res. Clin. Oncol. 2020, 146, 569-577. [CrossRef] [PubMed]

45. Wang, J.; Zhang, L.; Kang, D.; Yang, D.; Tang, Y. Activation of PGE2/EP2 and PGE2/EP4 signaling pathways positively regulate the level of PD-1 in infiltrating CD8(+) T cells in patients with lung cancer. Oncol. Lett. 2018, 15, 552-558. [CrossRef] [PubMed]

46. Miao, J.; Lu, X.; Hu, Y.; Piao, C.; Wu, X.; Liu, X.; Huang, C.; Wang, Y.; Li, D.; Liu, J. Prostaglandin E(2) and PD-1 mediated inhibition of antitumor CTL responses in the human tumor microenvironment. Oncotarget 2017, 8, 89802-89810. [CrossRef] [PubMed]

47. Cherukuri, D.P.; Cherukuri, D.P.; Chen, X.B.; Goulet, A.-C.; Young, R.N.; Han, Y.; Heimark, R.L.; Regan, J.W.; Meuillet, E.; Nelson, M.A. The EP4 receptor antagonist, L-161,982, blocks prostaglandin E2-induced signal transduction and cell proliferation in HCA-7 colon cancer cells. Exp. Cell Res. 2007, 313, 2969-2979. [CrossRef]

48. Heidegger, H.; Dietlmeier, S.; Ye, Y.; Kuhn, C.; Vattai, A.; Aberl, C.; Jeschke, U.; Mahner, S.; Kost, B. The Prostaglandin EP3 Receptor Is an Independent Negative Prognostic Factor for Cervical Cancer Patients. Int. J. Mol. Sci. 2017, 18, 1571. [CrossRef]

49. Remmele, W.; Stegner, H.E. [Recommendation for uniform definition of an immunoreactive score (IRS) for immunohistochemical estrogen receptor detection (ER-ICA) in breast cancer tissue]. Pathologe 1987, 8, 138-140.

50. Badmann, S.; Heublein, S.; Mayr, D.; Reischer, A.; Liao, Y.; Kolben, T.; Beyer, S.; Hester, A.; Zeder-Goess, C.; Burges, A.; et al. M2 Macrophages Infiltrating Epithelial Ovarian Cancer Express MDR1: A Feature That May Account for the Poor Prognosis. Cells 2020, 9, 1224. [CrossRef] 